\title{
Analysis on Ecological Economic Benefits of International Trade of Agricultural Products
}

\author{
Yu Xin \\ Xi’an International University, Xi’an, Shaanxi, 710077
}

Keywords: Ecological Economic Benefits, International Trade, Agricultural Products

\begin{abstract}
The internationalization trend of eco-environmental issues and the characteristics of international trade as a channel of interest "transmission" have led more and more countries and regions to pay attention to trade and ecological environment issues. The universal, unique externalities and versatility of agriculture, the close interdependence between agriculture and the natural ecological environment have made agricultural trade a focus of trade and ecological environment research. From the unilateral pursuit of trade economic interests in the past, to the realization of trade ecological environment, economic and social comprehensive interests, is the focus of research on agricultural trade.
\end{abstract}

\section{Introduction}

This paper will review the conclusions of the theory and method basis of eco-economic benefit evaluation of agricultural products trade--the principle of ecological economic benefit and the theory of ecological environment value. Drawing on the theory of agricultural externality and versatility, comprehensively and systematically analyze the externalities and versatility of agricultural trade, as well as the debate on "non-trade concerns" caused by agricultural versatility, and theoretically explore the ecological economic benefits of agricultural products trade. The source of the analysis provides an analytical basis for further research on the ecological and economic benefits of agricultural trade. On the basis of theoretical analysis, through the theoretical and empirical research on the relationship between international trade and economic growth, international trade and ecological environment, it is analyzed whether international trade can truly bring about ecological environment, economic and social benefits. Using the historical data of China's agricultural trade, through the quantitative analysis of the data, it is found that the impact of agricultural trade on the national economy, society and ecological environment and the changing trend. Based on this, the paper puts forward a new strategy for the development of China's agricultural trade under the concept of ecological economic benefits-the "dynamic comparative advantage" competition strategy and the "ecological trade" development strategy, and the policy measures that should be adopted to implement the two major strategies.

\section{Principles and evaluation methods of ecological economic benefits}

Since ecological benefits belong to the category of natural productivity, they have their own natural development and evolution laws, and economic benefits belong to the category of social productivity. The maximization of human "profit or utility" often leads people to have a tendency to pursue short-term and immediate interests. , leading to ecological damage, degradation of environmental quality, that is, the reduction of ecological benefits, and ultimately the loss of natural material basis for economic and social benefits. That is to say, if human economic activities excessively pursue economic benefits, it will result in low ecological benefits and even negative benefits. This has been proved by the history of Western economic development since the Industrial Revolution. If the externalities of human production and consumption activities are positive, their ecological benefits will increase and vice versa. Similarly, if the ecological benefits are excessively pursued, the economic benefits of economic entities will be suppressed, and the incentives and incentives for development will be lost. There is also a contradictory and unified relationship 
between economic benefits and social benefits. Since social benefits refer to the extent to which the social reproduction process meets the needs of society for the use of material and spiritual wealth and the consequences of subsequent society after meeting the demand. Therefore, the improvement of social benefits generally requires economic growth as a material prerequisite, without economic benefits as a guarantee, and the improvement of social benefits is also difficult to sustain in the long run. The level of social welfare in developed countries is generally higher than the reality of developing countries and can largely prove this judgment. However, the motive of maximizing profit of "economic man", the negative externality of economic activity and the failure of "market mechanism" often lead to the improvement of microeconomic interests and the reduction of social interests belonging to the macro category. If enterprises use a large number of advanced technologies to replace labor, while improving economic efficiency, it will result in a reduction in social benefits expressed by unemployment.

\section{Analysis of Ecological Economic Benefits of China's Agricultural Products Trade}

The eco-environmental benefits of agricultural trade are the continuation and realization of the functions of agro-ecological environment through trade. The "transfer" effect of international trade often causes the ecological environment between countries to "transfer" through the import and export of products, and affect each other. Due to the unification of natural reproduction and economic reproduction of agricultural production processes, the characteristics of eco-environmental effects of agricultural products trade are more obvious. It is precisely because of this that many WTO members focus on "non-trade concerns", mainly on the eco-environmental effects of agricultural products trade, and use this as an excuse to obstruct negotiations on agricultural and agricultural trade liberalization.

The social benefit of agricultural trade is a concrete reflection and embodiment of the social function of agriculture and agricultural trade. The social functions of agriculture and agricultural trade are manifested in many aspects, such as reducing poverty, replacing social welfare and social security, linking employment pressures, providing food security functions, and improving international political and trade relations. The reduction of poverty and the replacement of social welfare functions are mainly achieved with the increase in agricultural income and the fair process of agricultural income distribution. Therefore, this paper will analyze the effects of agricultural trade on employment and food security. From the point of view of the analysis, the US statistics on the relationship between export trade and employment have little significance for China's reference, because the high labor productivity and high capital intensity of the US export sector are not yet reachable by the Chinese export sector. Fan Aijun and the National Bureau of Statistics have the same measured data. Therefore, this paper uses their data as a reference to calculate the employment effect of agricultural trade. Considering that the employment ratio of resource-intensive agricultural products is low, the employment increase effect of resource-intensive product exports can be offset by the employment reduction effect caused by technological progress and capital substitution effect on labor. Therefore, when calculating the employment effect of agricultural products export, only Calculate the employment effect of labor-intensive agricultural exports. At the same time, considering the substitution effect of imported products on the production of domestic products, although the import of production materials can also create employment opportunities, the two can basically offset the overall employment effect. Therefore, this paper does not analyze the import effect of agricultural products trade.

\section{Agricultural trade development strategy and countermeasures under the concept of ecological economic benefits}

According to the analysis and measurement of the environmental negative externalities in the production process of different agricultural products and the occupation of land resources and water consumption per unit of product, the production of agricultural products with large negative externalities, large land resources per unit of products and high consumption of water resources is 
reduced. And export, expand the import of these products, and continuously improve the ecological environment and social benefits of agricultural trade. With the international trade of agricultural products and the import of foreign ecological resources, we can free up more domestic land, forests, grasslands, lakes and other places to enter the natural state of "cultivation and living", and can reduce the huge investment in artificial restoration of ecology, stabilize and improve China's own The long-term effects of the ecological restoration and treatment projects of "returning farmland to forests, grasslands, and lakes" have been implemented to promote the improvement of the domestic ecological environment and a virtuous circle. This is the basic content of the "ecological trade" development strategy.

Those who agree with the implementation of the protection trade policy believe that historically, many countries, especially developed countries, have implemented agricultural and agricultural product protection policies in the process of economic development, and have significantly increased their food and other agricultural products. The interests and income of farmers are guaranteed. 2 From the analysis of the proportion of China's agricultural population, the status of agricultural resources and the overall international competitiveness of agricultural products, China has great disadvantages and it is difficult to compete with developed countries. 3 More and more countries in the world are adopting various new trade protectionist measures to strengthen restrictions on the import of agricultural products in the name of protecting the ecological environment and the interests of domestic producers. Since the signing of the 4WTO "Agriculture Agreement", the developed countries that have implemented high subsidies for agriculture and agricultural production have not reduced their subsidies for agricultural production and exports, but have increased. At the same time, within the system, the discussion on the issue of "non-trade concerns" triggered by the versatility of agriculture has made the resistance to the liberalization of agricultural trade more and more.

When adopting a protection trade policy, it clearly distinguishes between the two meanings of "protection". One implication is the application of the term "protection", which is often derogatory in everyday language, to some of the concepts and requirements of the agricultural sector. For example, protecting the rights and interests of farmers, protecting cultivated land resources, and protecting the agricultural environment and water conservancy facilities. The protection requirements in this sense are justified and have important practical significance. There is no theoretical discussion necessary. The question is how to implement it effectively. The other is the agricultural and agricultural product protection policy in the economic sense. The protection here is based on the basic principles of the market economy. Its fundamental feature is to replace and distort the market mechanism through the government's domestic price intervention and border control measures. The role is to achieve the goal of stimulating the production of domestic food and other agricultural products and transferring income to the agricultural population. Foreign agricultural protection policies usually refer to protection policies in the economic sense. Whether agricultural protection policies in this sense should be implemented should be carefully considered.

However, under the premise of the continuous opening up of agriculture and the pursuit of eco-economic benefits of agricultural trade, it is necessary to coordinate the three policies, and as long as the design is reasonable, the coordination between the three policies can be fully achieved. . For example, in the industrial policy, encourage agricultural production organizations to develop agricultural industry integration organizations in accordance with the principles of ecological industry supply chain or "circular economy", and adopt appropriate subsidies rather than taxation methods to encourage agricultural industrialization organizations to adopt resource conservation. Clean production technology encourages the import of agricultural varieties, advanced planting technology and environmentally friendly processing technology equipment in trade policy, and promotes green certification, sales channel development and market information services for "environmentally friendly" agricultural products. Then, it is possible to simultaneously promote the development of agricultural industrialization organizations, save agricultural resources, improve the agricultural ecological environment, and promote the expansion of agricultural exports, while achieving the objectives of the three policies. 
China's comparative advantage and international competitiveness in labor-intensive agricultural products are relatively high, but the existing international competitiveness of this part of agricultural products is higher than the potential international competitiveness, that is, the international competitiveness has a gradual decline, mainly due to domestic land. The opportunity cost and labor cost of natural resources such as water are rising. To a large extent, this indicates that to continue or continuously improve the comparative advantages of labor-intensive agricultural products, so that the export of this part of agricultural products to obtain long-term economic benefits and social employment benefits, it is necessary to increase the labor productivity of its unit products. The improvement of labor productivity depends on the comprehensive quality and labor skills of laborers. The most effective way to improve the overall quality and skills of workers is to increase investment in education in rural areas, investment in skills training for farmers, and rural medical, health and safety conditions. Improvement - that is, to strengthen investment in agricultural human capital. This is an inevitable choice for China's labor-intensive agricultural products to maintain a "dynamic comparative advantage" for a long time.

\section{Conclusion}

The wide distribution of agricultural production and the inseparability of natural and economic reproduction make the externality of agriculture show stronger universality, particularity and long-term. The versatility of agriculture to social and economic development triggered by externalities determines that the non-commodity output function of agriculture and the function of commodity output have equally important contributions to the development of the national economy, and that the output of agricultural commodities is The proportion of economic commodity output is decreasing, and the non-commodity output function of agriculture will play an increasingly important role in the development of human society. This requires future agricultural development to pursue the coordination and unification of economic, social and ecological environmental benefits.

\section{References}

[1] Cheng Guodong. Virtual Water-A New Idea of China's Water Resources Security Strategy [J]. Chinese Academy of Sciences, 2003( 4) : $260 \sim 264$

[2] Luo Yili, Long Aihua, Huang Shou. Virtual Soil Strategy and Social Management of Sustainable Utilization of Land Resources [J]. Glacier Frozen Soil Issues, 2004( 10) : 624 630

[3] Yan Zhiqiang, Yan Zhangxiong, Hu Baoqing, Huang Zongkui. Theoretical Discussion on Virtual Land, Virtual Land Strategy and Regional Land Resources Optimal Allocation Management [J]. Guangxi Social Sciences, 2007( 10) : $70 \sim 74$

[4] Liu Hongmei, Wang Keqiang, Shi Fang. An Empirical Analysis of China's Grain Virtual Land Resources Imports. China's Rural Economy[J], 2007(11) : 26 34

[5] Cao Huimin, Luo Huasong. Game Analysis of Virtual Land Trade Balance [J]. Modern Business \& Industry, 2012( 7) : $14 \sim 17$ 